\title{
Mixoma auricular y carcinoma de colon
}

\section{Sr. Director:}

El mixoma representa el tumor cardíaco benigno más frecuente en el adulto. Generalmente es único, aunque se han descrito casos de aparición múltiple; así, una forma de mixoma familiar se transmite de forma autosómica dominante, se presenta en pacientes jóvenes y se puede asociar a adenoma de hipófisis, tumores testiculares y fibroadenomas mixoides mamarios $^{1,2}$.

Habitualmente se localiza en la aurícula izquierda y con menor frecuencia en la derecha, suele estar adherido por un pedículo al septo interauricular.

Pueden cursar de forma totalmente asintomática y descubrirse en el curso de una exploración ecocardiográfica ${ }^{2}$.

Los mixomas localizados en la aurícula izquierda pueden provocar insuficiencia cardíaca, síncope o muerte súbita. Hay descritos casos de embolias en las arterias coronarias, cerebrales, renales y en las extremidades inferiores $1,3,4$.

También pueden presentarse trastornos del ritmo y de la conducción cardíaca ${ }^{2}$.

La aparición de un síndrome constitucional es más frecuente en los tumores malignos, aunque en el mixoma puede observarse hasta en el $80 \%$ de los casos y puede originar planteamientos de diagnóstico diferencial con neoplasias de otra localización, infecciones ocultas o enfermedades del colágeno².

El ecocardiograma es el mejor método diagnóstico y cuando se utiliza el transesofágico, dada su mayor definición, se pueden detectar tumores pequeños que no se visualizarían con el ecocardiograma convencional ${ }^{2}$.

El tratamiento consistirá en la extirpación quirúrgica, pero pueden presentarse recidivas hasta en el 5\% de los casos? ${ }^{2}$.

El cáncer de colon y recto es el segundo tumor en incidencia después del cáncer de pulmón. El tipo histológico más frecuente es el adenocarcinoma en el 90$95 \%$ de los casos. Con cierta frecuencia se detectan casos de neoplasias múltiples, por lo que es obligada la realización de colonoscopia y enema opaco ${ }^{5}$.
Se denominan tumores primarios múltiples cuando existe más de un tumor en el momento del diagnóstico - bien si se diagnostica un segundo tumor en el curso del seguimiento; es condición imprescindible que los tumores sean distintos histobiológicamente ${ }^{3}$.

En una revisión realizada recientemente se han encontrado asociación del mixoma con cánceres de pulmón, mama, riñón, hígado, páncreas, piel, tiroides, ovario. Sin embargo, no se han encontrado casos de asociación con cáncer de colon ${ }^{3}$.

Recientemente hemos tenido ocasión de diagnosticar un nuevo caso y nos parece interesante presentarlo brevemente por su rareza.

Varón de 77 años de edad, con antecedentes personales de EPOC en tratamiento con inhaladores broncodilatadores. Acudió a urgencias por un cuadro de dolor abdominal de unas horas de evolución, no acompañado de fiebre ni vómitos.

A la exploración física se apreció un abdomen distendido, doloroso de modo difuso y con contractura muscular, más acusada en el hemiabdomen inferior.

El hemograma, hemostasia y bioquímica fueron normales.

Radiografía de tórax: no cardiomegalia, campos pulmonares claros.

Electrocardiograma, sin alteraciones significativas.

Con el diagnóstico de abdomen agudo se realizó una laparotomía en la que se observó la perforación de un divertículo localizado en el colon descendente y una neoplasia de sigma muy próxima al divertículo. Se efectuó una resección segmentaria del colon descendente y del sigma, dejando asimismo una colostomía.

El diagnóstico histológico fue de adenocarcinoma moderadamente diferenciado que alcanzaba hasta la grasa periserosa, los bordes quirúrgicos se encontraban libres y los ganglios linfáticos analizados no mostraban infiltración tumoral. El estadio por lo tanto, era un B 2 de Astler y Coler.

No presentó complicaciones posteriores y fue dado de alta a los 12 días de la intervención quirúrgica.

Diez días más tarde acudió a urgencias por un cuadro de disnea de esfuerzos moderados, ortopnea de 2 


\section{F. Marcos Sánchez y cols.}

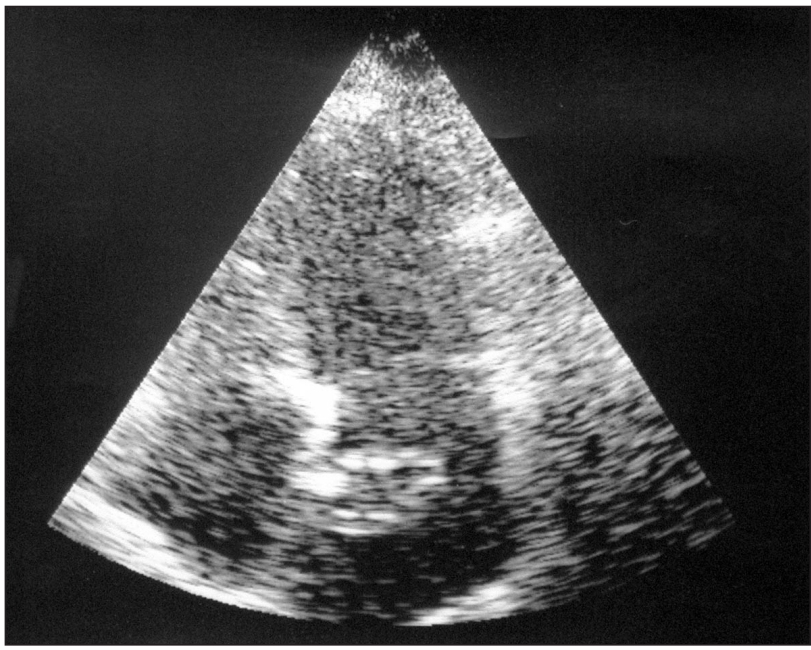

Fig. 1. La aurícula izquierda se encuentra dilatada, observándose una masa sólida de $37 \times 24 \mathrm{~mm}$, unida por un pedículo a la zona media del septo.

almohadas, palpitaciones y edemas de miembros inferiores.

La radiografía del tórax mostró un edema intersticial bilateral y en el ECG se observó una fibrilación auricular rápida.

Fue diagnóstico de insuficiencia cardíaca, mejorando tras el tratamiento médico oportuno.

Un ecocardiograma mostró una dilatación global del ventrículo izquierdo, fracción de eyección del ventrículo izquierdo del 40\%, la aurícula izquierda se encontraba dilatada, observándose una masa sólida de $37 \times 24 \mathrm{~mm}$, unida por un pedículo a la zona media del septo, dentro de la aurícula izquierda (Fig. 1). No producía obstrucción en el llenado aurículo-ventricular, era compatible con un mixoma.

También se realizó una coronariografía, que fue normal.

Posteriormente se procedió a la resección del mixoma en el hospital Virgen de Salud, de Toledo, con una evolución clínica posterior favorable. El diagnóstico histológico confirmó la sospecha de mixoma auricular.

El paciente decidió no realizar tratamiento adyuvante de quimioterapia para su cáncer de colon en estadio B 2.

Las revisiones posteriores de su cáncer de colon han sido normales con un seguimiento actual de 9 meses y las ecografías cardíacas realizadas tras la cirugía cardíaca han sido asimismo normales.

\section{Bibliografía}

1. Colucci WS, Braunwald E. Tumores primarios del corazón. En Braunwald E. Tratado de Cardiología. Ed. Interamericana. New York 1993; 1620-35.

2. Abad C. Tumores cardíacos (I). Generalidades. Tumores primitivos benignos. Rev Esp Cardiol 1998; 51:10-20.

3. García F, Gamallo C, Gil M. Registro Nacional de Tumores Cardíacos (memoria 1996-1997). Rev Esp Cardiol 1999; 52:13-20

4. Abad C, Serra J, Condom E, Bosch X, Mestres CA, Paré JC. Infarto de miocardio en una mujer joven con un mixoma auricular izquierdo. Rev Esp Cardiol 1989; 42:485-8.

5. Abad A. Cáncer de colon y recto. En Oncología Médica de Rosell R, Abad A, Monzo M, Molina F. Ed. Ergón Madrid 1995; 273-85.

\section{F. Marcos Sánchez* ${ }^{*}$ A. Vázquez García**, I. Albo Castaño*, F. M. Gómez Soto*, A. Viana Alonso*, F. Juárez Ucelay* * Servicio de Medicina Interna ** Servicio de Cardiología Hospital № Sa del Prado Talavera de la Reina (Toledo)}

